\title{
Correction to: A Comprehensive Analysis of Postmarket Surveillance Study Orders: Device Characteristics, Study Statuses, Outcomes, and Potential Contributions
}

\author{
Chie Iwaishi, $\mathrm{BS}^{1} \cdot$ Kiyotaka Iwasaki, $\mathrm{PhD}^{1,2}$ (])
}

Published online: 10 February 2020

(c) The Author(s) 2020

\section{Correction to: Therapeutic Innovation \& Regulatory Science https://doi.org/10.1007/s43441-020-00113-7}

In the original article Fig. 3 is not displayed correctly. The corrected Fig 3 is as follows.

The original article can be found online at https://doi.org/10.1007/ s43441-020-00113-7.

Kiyotaka Iwasaki

iwasaki@waseda.jp

1 Cooperative Major in Advanced Biomedical Sciences, Tokyo Women'sMedical University and Waseda University Joint Graduate School, WasedaUniversity, Tokyo, Japan

2 Faculty of Science and Engineering, Waseda University, 2-2 Wakamatsu-cho, Shinjuku, Tokyo 162-8480, Japan 


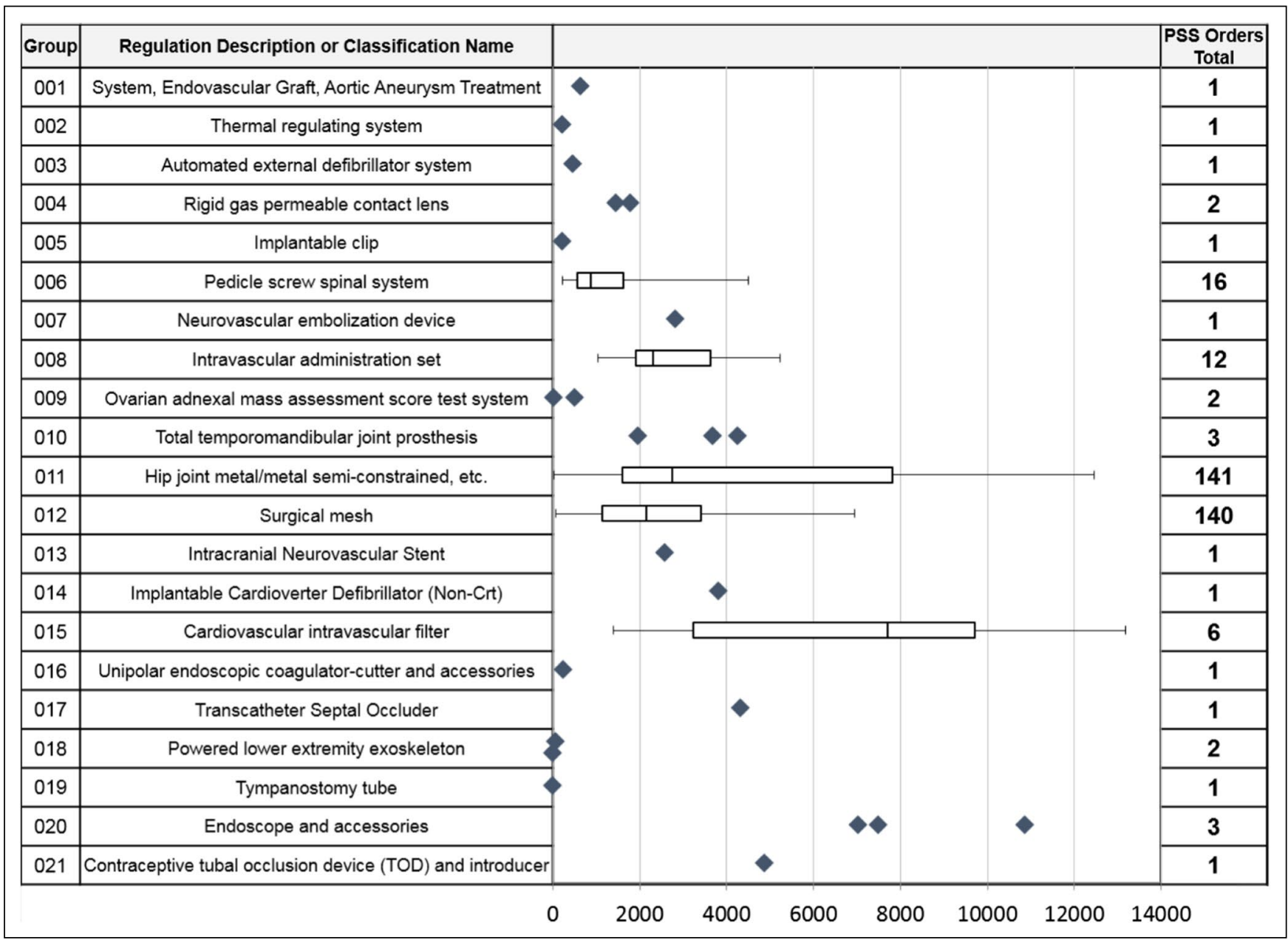

Figure 3. The Number of Days From the First Market Approval/Clearance to 522 Orders by Issue Category.

Publisher's Note Springer Nature remains neutral with regard to jurisdictional claims in published maps and institutional affiliations. 